\title{
BMJ Open Attitudes towards vaccines and intention to vaccinate against COVID-19: a cross-sectional analysis - implications for public health communications in Australia
}

Joanne Enticott (1) ,1,2 Jaskirath Singh Gill (D) , ${ }^{1}$ Simon L. Bacon (1) ,3,4

Kim L. Lavoie (D) ${ }^{3,5}$ Daniel S. Epstein (D) , ${ }^{6}$ Shrinkhala Dawadi, ${ }^{1}$ Helena J Teede, ${ }^{1,2}$ Jacqueline Boyle, ${ }^{1,7}$ for the iCARE Study Team

To cite: Enticott J, Gill JS, Bacon SL, et al. Attitudes towards vaccines and intention to vaccinate against COVID-19: a cross-sectional analysis-implications for public health communications in Australia. BMJ Open 2022;12:e057127. doi:10.1136/ bmjopen-2021-057127

- Prepublication history and additional supplemental material for this paper are available online. To view these files, please visit the journal online (http://dx.doi.org/10.1136/ bmjopen-2021-057127).

JE and JSG are joint first authors.

Received 07 September 2021 Accepted 07 December 2021

Check for updates

(c) Author(s) (or their employer(s)) 2022. Re-use permitted under CC BY-NC. No commercial re-use. See rights and permissions. Published by BMJ.

For numbered affiliations see end of article.

Correspondence to Dr Joanne Enticott; joanne.enticott@monash.edu

\section{ABSTRACT}

Objective To examine SARS-CoV-2 vaccine confidence, attitudes and intentions in Australian adults as part of the iCARE Study.

Design and setting Cross-sectional online survey conducted when free COVID-19 vaccinations first became available in Australia in February 2021.

Participants Total of 1166 Australians from general population aged 18-90 years (mean 52, SD of 19). Main outcome measures Primary outcome: responses to question 'If a vaccine for COVID-19 were available today, what is the likelihood that you would get vaccinated?'.

Secondary outcome: analyses of putative drivers of uptake, including vaccine confidence, socioeconomic status and sources of trust, derived from multiple survey questions. Results Seventy-eight per cent reported being likely to receive a SARS-CoV-2 vaccine. Higher SARS-CoV-2 vaccine intentions were associated with: increasing age (OR: 2.01 (95\% Cl 1.77 to 2.77)), being male (1.37 (95\% $\mathrm{Cl} 1.08$ to 1.72$))$, residing in least disadvantaged area quintile (2.27 (95\% Cl 1.53 to 3.37$)$ ) and a self-perceived high risk of getting COVID-19 (1.52 (95\% Cl 1.08 to 2.14)). However, $72 \%$ did not believe they were at a high risk of getting COVID-19. Findings regarding vaccines in general were similar except there were no sex differences. For both the SARS-CoV-2 vaccine and vaccines in general, there were no differences in intentions to vaccinate as a function of education level, perceived income level and rurality. Knowing that the vaccine is safe and effective and that getting vaccinated will protect others, trusting the company that made it and vaccination recommended by a doctor were reported to influence a large proportion of the study cohort to uptake the SARS-CoV-2 vaccine. Seventyeight per cent reported the intent to continue engaging in virus-protecting behaviours (mask wearing, social distancing, etc) postvaccine.

Conclusions Most Australians are likely to receive a SARS-CoV-2 vaccine. Key influencing factors identified (eg, knowing vaccine is safe and effective, and doctor's recommendation to get vaccinated) can inform public health messaging to enhance vaccination rates.
Strengths and limitations of this study

- This research captured a large, representative sample of the adult Australian population across age, sex, location and socioeconomic status around the time that free COVID-19 vaccinations first became available to Australians in February 2021.

- We have self-reported Australian uptake intentions and attitudes on general vaccines and COVID-19 vaccine and intent to continue engaging in virusprotecting behaviours (mask wearing, social distancing, etc) post-SARS-CoV-2 vaccine.

- We examine a range of drivers and factors that may influence intent to get the SARS-CoV-2 vaccine uptake, including vaccine confidence, demographics and socioeconomic status.

- The survey is based on established behavioural theories and is the Australian arm of the international iCARE survey that to date has collected global comparative information from over 105000 respondents in 140 countries.

- Our survey was only available in English, which may have led to an under-representation of ethnic groups, and participation was voluntary, so our sample may be prone to selection bias from those with more interest or engagement in COVID-19.

\section{INTRODUCTION}

The SARS-CoV-2 (COVID-19) pandemic has resulted in an estimated 211 million cases and 4.43 million deaths worldwide, including 44 028 cases and 981 deaths in Australia, ${ }^{1}$ as of August 2021. The R0 value, which represents the average number of people a single infected person can expect to transmit a virus to in a completely susceptible population, has increased from 2 to 3 for the original Wuhan SARS-CoV-2 virus to 5-6 for the Delta variant of the SARS-CoV-2 virus currently dominating the world. ${ }^{2}$ While vaccinated individuals can 
be infected with and transmit SARS-CoV-2, the vaccines reduce the likelihood for serious illness and subsequent hospitalisation and death by greater than $80 \%$ and $85 \%{ }^{3}$ Therefore, vaccinated populations are likely to pivot from the prevention of SARS-CoV-2 infections to instead accepting that the virus is endemic with the aim to minimise serious illness, hospitalisation and death. ${ }^{45}$

Minimising serious illness, hospitalisations and deaths requires high vaccination rates for SARS-CoV-2 and ongoing preventative health behaviours such as physical distancing and wearing face masks ${ }^{6}$ to protect the unvaccinated (eg, young children) and those in which the vaccine is less effective such as the immunocompromised. ${ }^{7}$ It is now clear that combined behavioural strategies and vaccination (including boosters) are the pathway out of perpetual strict population level restrictions, which in Australia have included limiting gatherings, restricting education and work attendance, stay at home orders and closing both state and international borders. ${ }^{89}$ Although these restrictions have been effective at reducing COVID-19 transmission and have prevented large numbers of deaths to date, ${ }^{10}{ }^{11}$ they come with serious economic, social and mental health costs that are unacceptable in the long term. ${ }^{8}$

Australia is a country with a strong public health record, backed by high socioeconomic status, low population density and a universal free healthcare system. ${ }^{12}$ There is also high vaccine uptake in general. For example, rates of hepatitis B immunisation among 1 year olds in Australia was $95 \%$ in 2020 , which was higher when compared with other high-income countries such as the USA (91\%) and Canada $(84 \%){ }^{13}$ These factors, alongside the strict policies including lockdowns, and Australia being an island nation, making it easier to secure borders, had contributed to Australia largely controlling the pandemic prior to the emergence of the Delta variant. ${ }^{12}$ However, having a low SARS-CoV-2 vaccination rate, due to public concerns over the safety of the AstraZeneca vaccine and a lack of supply of the mRNA vaccines, Australia has been particularly susceptible to recent delta variant outbreaks. ${ }^{14}$

Vaccine uptake is critical to the long-term management of the COVID-19 pandemic. To date, over $11 \%$ of the world's population have received at least one dose of a SARS-CoV-2 vaccine. ${ }^{3}$ Vaccine supply and uptake needs to be accelerated globally to enhance protection against COVID- $19 .{ }^{15}$ Vaccine hesitancy and vaccine confidence are key determinants of vaccine uptake, and it is vital to understand factors associated with hesitancy. Vaccine confidence refers to the trust in the vaccines, the providers who administer it, and the science, processes and policies behind it. ${ }^{16}$ Vaccine hesitancy is the sense of uncertainty in vaccines for a particular belief or reason. ${ }^{16}{ }^{17}$ Vaccine hesitancy and reduced confidence may result in the refusal of, or delay in the acceptance of, a vaccination. ${ }^{18}$ Both vaccine hesitancy and confidence are complex and can be influenced by many determinants, as identified by the Strategic Advisory Group of Experts on Immunisation working group on vaccine hesitancy, ${ }^{18}$ and are broadly grouped into three categories: (1) contextual socio-politico-cultural factors, (2) individual and group influences and (3) vaccine specific factors (see table 1 for examples). ${ }^{8}$ Existing work on population intentions around the SARS-CoV-2 vaccines is emerging globally. ${ }^{19}$ A French study conducted early in the pandemic (March 2020 ) found that $26 \%$ of participants would not accept to receive a SARS-CoV-2 vaccine if it became available. ${ }^{20}$ This was more prevalent among those in lower income categories, young women and those older than 75 years of age. In the UK, $14 \%$ of participants in a study were unwilling to receive a vaccine, with $23 \%$ being unsure. ${ }^{6}$ Similar to the French study, females and those from lower income groups, reported being less likely to have a SARS-CoV-2 vaccine if available. $^{6}$

The vaccine confidence index (VCI) consists of four questions to understand a person's perceptions about if vaccines are safe, important, effective and/or compatible with religious beliefs. ${ }^{21}$ The VCI was developed following the identification of key drivers that influence the public's confidence in vaccines. ${ }^{16}$ Data have suggested approximately one in five Australians were hesitant regarding SARS-CoV-2 vaccines in the early stages of the COVID-19 pandemic in March/April 2020, with 14\%-24\% respondents being unsure or unwilling to get a vaccine if available. ${ }^{22} 23$

This study identifies characteristics of Australians who intend or did not intend to get the vaccine in March 2021. Australia, as an island nation that overall had minimal to no community transmission of SARS CoV-2 prior to the delta outbreak, offers a unique case study to gain insights and inform mitigation strategies that could be applied globally. As attitudes towards the SARS-CoV-2 vaccine may vary over time, this new information will be able to inform

Table 1 Vaccine hesitancy and confidence are complex and can be influenced by many determinants, as identified by the Strategic Advisory Group of Experts on Immunization working group on vaccine hesitancy

\begin{tabular}{ll}
\hline Categories & Examples \\
\hline Contextual socio-politico-cultural factors & Compatibility of vaccination with religious beliefs. \\
Individual and group influences & Personal perception of the vaccine. \\
& - Influences from the social and peer environment. \\
Vaccine-specific factors & Issues directly related to the vaccine or vaccination. \\
& Accelerated development of vaccines for SARS-CoV-2 may increase safety \\
& concerns in the population. \\
\hline
\end{tabular}


current public health campaigns and policy ${ }^{23} 24$ and assist with effectively targeting those who currently have lower vaccine intentions. Hence, here we aim to characterise the beliefs, intentions and hesitancy of Australians towards vaccines generally (importance, safety and efficacy), and to SARS- CoV-2 specifically, to inform strategies to address this and increase uptake.

\section{METHODS}

This project is part of the Australian arm of the International COVID-19 Awareness and Responses Evaluation (iCARE) study, which is investigating people's understanding, attitudes, beliefs and actions towards the COVID-19 pandemic. $^{25}$ The Montreal Behavioural Medicine Centre, the lead institution, ${ }^{26}$ has research ethics board approval from the Comité d'éthique de la recherche du CIUSSS-NIM (Centre intégré universitaire de santé et de services sociaux du Nord-de-l'île-deMontréal), approval\#: 2020-2099/25-03-2020. The iCARE aims, measures and survey construction are reported in detail elsewhere, ${ }^{25}$ and the survey results and publications resulting from this international collaboration are available at www.icarestudy.com. This paper reports the analysis of the new vaccination questions asked in the third round of the Australian longitudinal survey, ${ }^{27}$ which comprised a national representative sample (survey included in online supplemental documents). The third round included new questions on attitudes towards the COVID-19 vaccination and intention to vaccinate against COVID-19 in Australia; therefore, longitudinal comparison with earlier rounds ${ }^{27}$ is not possible. Here we report the nationally representative cross-sectional analysis of respondents in this third survey conducted in early 2021.

\section{Sampling}

Survey respondents were recruited by an online sampling provider that sent out invitations between 14 February and 7 March 2021. By this time, Australia had recorded 28947 COVID-19 cases with variable virus impacts and policy approaches across states and a lack of national coordination. At a state level, Western Australia was lifting a lockdown (5 February 2021), and Victoria had entered a 'circuit breaker', 5-day lockdown having had more than 100 days in lockdown in 2020 (12 February 2012). The first public COVID-19 vaccinations were available on the 21 February 2021.

Electronic survey invitations were emailed to approximately 12000 adults having a residential address in Australia and briefly described the survey content, estimated survey duration and a link to the online survey. The first page of the survey described the study and its purpose and advised readers that continuing to the next page would be an indicator of consent to participate in the study. All participants who completed the online survey were reimbursed by ISO 26362 as per industry requirements. Representative sampling for key demographics of the Australian population was done using quota sampling for age, sex and residential location (state/territory and remoteness area) with quotas set to reach the maximum numbers as indicated by the proportion shown for the usual Australian population in table 2. After 4 days of recruitment and from then on approximately weekly, the demographics (age, sex and broad location of residence (state/rurality)) of participants with completed surveys were examined, and further sampling was targeted to underrepresented groups to align with population characteristics. Non-responders characteristics were not collected as this was not permitted by the sampling company in this study. In previous arms of the iCARE survey in Australia, the response rate was approximately $10 \%$ for new participants, which the sampling company reported was typically expected for their online surveys of similar length (using only email recruitment and electronic surveys). To minimise non-response bias, the sampling company would send reminders to potential participants two times approximately 1 week apart (provided they did not belong to a quota that had been reached).

\section{Patient and public involvement}

As part of the main iCARE study, there are several community collaborators who provide continual input into the development of the survey design, ensuring that the items are relevant and appropriately worded. In addition, members of the general public have been engaged to contribute to the dissemination of study results through sharable infographics made available on the study website. For Australia, the survey was reviewed by the Monash Partners Consumer and Carer group and involved two members paid for their time to identify text that was not clear or irrelevant to Australia and recommend alternative wording and areas to clarify. Other community members and contacts of the researchers provided input into the timing to complete the survey, and subsequently this feedback resulted in the survey being shortened to reduce participant burden.

\section{Analysis plan}

Participant demographic data included residential postcode, which were mapped to the Australian Bureau of Statistics remoteness areas and socioeconomic index for areas. ${ }^{28}$ Specifically, the index of relative socioeconomic disadvantage (IRSD) was applied and divided into five quintiles, from 1 (most disadvantaged) to 5 (most advantaged). Ethnicity information provided by participants was used to make two groupings of 'Australian/New Zealand/UK' and everyone else.

Descriptive statistics reported the participant demographics and attitudes for a series of vaccine-related questions including the VCI. ${ }^{16} 21$

To characterise the beliefs, intentions and hesitancy of Australians towards vaccines generally and SARS- CoV-2 vaccines specifically, a series of univariate logistic regressions were done with dichotomous outcomes. Responses were dichotomised using the most extreme positive 
Table 2 Participant demographics $(n=1166)$

\begin{tabular}{lc}
$\begin{array}{l}\text { Australian } \\
\text { population } \\
\text { (\% unless } \\
\text { otherwise } \\
\text { indicated) }\end{array}$ & $\begin{array}{l}\text { Sample n } \\
\text { (\%) 1158 }\end{array}$ \\
\hline 39 & 51.7, \\
& 19.3
\end{tabular}

\begin{tabular}{|c|c|c|}
\hline Age (median, IQR) & 38 & $53,37.5$ \\
\hline \multicolumn{3}{|l|}{ Age breakdown* (\%) } \\
\hline $18-29$ & 19 & $214(18)$ \\
\hline $30-39$ & 19 & $175(15)$ \\
\hline $40-49$ & 17 & $142(12)$ \\
\hline $50-59$ & 16 & $148(13)$ \\
\hline $60-69$ & 14 & $143(12)$ \\
\hline $70+$ & 15 & $336(29)$ \\
\hline \multicolumn{3}{|l|}{$\operatorname{Sex}^{*}(\%)$} \\
\hline Males & 50 & $583(50)$ \\
\hline Females & 50 & $572(49)$ \\
\hline Others/prefers not to answer & 0 & $8(0.7)$ \\
\hline \multicolumn{3}{|l|}{ Area of residence $\dagger(\%)$} \\
\hline Urban/city/suburban/regional & 90 & $979(87)$ \\
\hline Rural/country & 10 & $142(13)$ \\
\hline $\begin{array}{l}\text { I don't know/prefer not to } \\
\text { answer }\end{array}$ & - & $5(0.4)$ \\
\hline \multicolumn{3}{|l|}{ Location by state/territory (\%) } \\
\hline New South Wales & 32 & $254(22)$ \\
\hline Victoria & 26 & $561(48)$ \\
\hline Queensland & 20 & $163(14)$ \\
\hline South Australia & 7 & $76(7)$ \\
\hline Western Australia & 10 & $82(7)$ \\
\hline Tasmania & 2 & $14(1.2)$ \\
\hline Australian Capital Territory & 2 & $9(1)$ \\
\hline Northern Territory & 1 & $6(1)$ \\
\hline Missing & - & $1(0)$ \\
\hline
\end{tabular}

Highest education level attained $\ddagger$

(\%)

\begin{tabular}{llc}
$\begin{array}{l}\text { Graduate/postgraduate/ } \\
\text { university degree }\end{array}$ & 52 & $432(47)$ \\
$\begin{array}{l}\text { Technical and Further } \\
\begin{array}{l}\text { Education (TAFE)/secondary or } \\
\text { high school }\end{array}\end{array}$ & $560(50)$ \\
\hline $\begin{array}{l}\text { Primary school or less } \\
\text { I don't know/prefer not to } \\
\text { answer }\end{array}$ & 3 & $12(1)$ \\
\hline $\begin{array}{l}\text { Essential worker (\%) } \\
\text { Healthcare workers }\end{array}$ & $19(2)$ \\
& 13 (including \\
social & $80(7)$ \\
\hline $\begin{array}{l}\text { QRSD quintile (\%) } \\
\text { disadvantile 1-most }\end{array}$ & assistance) \\
\hline
\end{tabular}

Continued
Table 2 Continued

\begin{tabular}{lll}
\hline & $\begin{array}{l}\text { Australian } \\
\text { population } \\
\text { (\% unless } \\
\text { otherwise } \\
\text { indicated) }\end{array}$ & $\begin{array}{l}\text { Sample n } \\
\text { (\%) 1158 }\end{array}$ \\
\hline Quintile 2 & 20 & $198(17)$ \\
\hline Quintile 3 & 20 & $235(20)$ \\
\hline Quintile 4 & 20 & $238(20)$ \\
\hline $\begin{array}{l}\text { Quintile 5 - least } \\
\text { disadvantaged }\end{array}$ & 20 & $345(30)$ \\
\hline Ethnicity§ (\%) & & \\
\hline Australian/New Zealand/UK & 73 & $580(50)$ \\
\hline $\begin{array}{l}\text { Other } \\
\text { Missing }\end{array}$ & 27 & $155(13)$ \\
\hline
\end{tabular}

Where applicable, variable categories have been collapsed to allow for concordance with national data published by the Australian Bureau of Statistics (ABS).

†The total Australian population was 25704340 as of March 2021; the total population and percentage breakdowns by age, sex and state of residence are obtained from the Australian Bureau of Statistics, ${ }^{49}$ who provide a quarterly release of their official estimates of this demographic data. Age is presented in 10 -year bands, and the first band that is comparable with the current study is $20-29$ years. The proportion of Australians by age is calculated as the proportion of those 20 years or over. \#Estimates for percentage of population by area of residence were obtained from the ABS, who release these data yearly. ${ }^{50}$ $\S$ Estimates for the percentage of population by level of education were obtained from the ABS, who release these data yearly. ${ }^{51}$

ПNational estimates for ethnicity were obtained by assessing the 'country of birth' data provided by the ABS 2016 Census. Whereas the survey 'ethnicity' variable was created using survey responses to the ethnicity item.

IRSD, index of relative socioeconomic disadvantage.

response, for example, 'Always' versus other. To examine robustness, regressions were repeated by redichotomising outcomes to include the two most extreme responses instead of one. Unlike in similar analyses, ${ }^{21}$ our outcomes could not be examined using ordinal logistic regression because of low numbers in some response categories.

Possible predictors examined in the logistic regressions, included age, sex, essential worker status, belief that a participant is at high risk, residential area, influenza vaccination status, education level, ethnicity, perceived income level and IRSD quintile. Ethnicity data were missing for 431 participants; therefore, these results were exploratory only. Responses to the VCI questions were also examined. All results are displayed as ORs, with 95\% CIs.

Sensitivity analyses involved Bayesian logistic regression to enabled global comparisons with a recent Lancet publication $^{21}$ and were conducted on the same outcome variables as in the logistic regressions. Normal priors $(0,1)$ were set for each regression parameter and used 5000 burn-in steps and 50000 sampling iterations. Statistical 
analyses used STATA SE/V.16. Significance level was set as $<0.05$.

\section{RESULTS}

There were 1166 survey respondents in this cross-sectional analysis. Response rate was approximately $10 \%$ for new participants and $60 \%$ for those in the longitudinal arm. ${ }^{27}$ Ages ranged from 18 to 90 years with a mean of 51.7 years (table 2), similar to the Australian population, apart from an overly represented group of participants aged 70 years or more. Sampling ensured a reasonable representativeness across sex, rurality and the three largest states (New South Wales, Victoria and Queensland). Education levels were similar to the Australian population. Less than half of participants $(45 \%)$ were in full-time or part-time work, lower than national statistics reported for the same time period $(63 \%)$, and likely due to the overly represented $70+$ years age group. Fifteen per cent reported being essential workers, with $7 \%$ healthcare workers. There was minimal missing data (table 2), except for ethnicity, with $50 \%$ respondents identifying as Australian/UK/New Zealand (NZ) $(\mathrm{n}=580), 13 \%$ as other $(\mathrm{n}=155)$ but $37 \%$ were missing $(\mathrm{n}=431)$.

Sixty-five per cent of participants generally accept routine vaccines for themselves or for their children, with $6 \%$ either rarely or never accepting vaccinations (table 3). At the time of this study, only 27 (2\%) participants had already received at least one dose of a COVID-19 vaccination. The majority $(78 \%)$ reported that they were likely to get the SARS-CoV-2 vaccine (table 3), and $15 \%$ of all participants were either unlikely or very unlikely to get the SARS-CoV-2 vaccine. Seventy-two per cent of our study cohort did not believe that there were at a high risk of being infected with COVID-19.

The VCI questions showed most Australians (>60\%) strongly agreed on the safety, importance and effectiveness of general vaccines (figure 1). Fifty-seven per cent strongly agreed that general vaccines are compatible with their religious beliefs (figure 1). Approximately $10 \%$ of participants did not know whether vaccines are safe or effective (figure 1).

\section{Predictors for vaccine uptake}

Determinants that were similar for both general (table 4) and SARS-CoV-2 vaccine uptake intention (table 5) included:

Higher likelihood of vaccine uptake was significantly associated with:

- Increasing age with OR=1.6 (95\% CI 1.4 to 1.8 ) and $\mathrm{OR}=2.0$ (95\% CI 1.8 to 2.3) for general and SARS$\mathrm{CoV}-2$ vaccine, respectively, residing in the least disadvantaged areas SES quintile $(\mathrm{OR}=2.1 \quad(95 \%$ CI 1.4 to 3.2) and 2.7 (95\% CI 1.5 to 3.4) for general and SARSCoV-2 vaccines).

- Identifying as Australian/NZ/UK with an $\mathrm{OR}=2.3$ (95\% CI 1.6 to 3.3 ) and 1.9 (95\% CI 1.3 to 2.7 ) for general and SARS-CoV-2 vaccines; however, as noted
Table 3 Uptake intentions and attitudes on general vaccines and COVID-19 vaccine and intent to continue engaging in virus-protecting behaviours (mask wearing, social distancing, etc) post-COVID-19 vaccine

\begin{tabular}{lc}
\hline & $\mathbf{n}(\%)$ \\
\hline $\begin{array}{l}\text { Had already received at least } 1 \text { dose of } \\
\text { COVID-19 vaccine }\end{array}$ & $27(2)$ \\
Likelihood of getting COVID-19 vaccine if it were available \\
today \\
$\quad$ Extremely likely & $597(53)$ \\
Somewhat likely & $283(25)$ \\
Unlikely & $88(8)$ \\
Very unlikely & $83(7)$ \\
\hline I don't know/prefer not to answer & $80(7)$ \\
Generally accept vaccines for yourself or for your children \\
Always & $736(65)$ \\
Mostly & $232(21)$ \\
Sometimes & $100(9)$ \\
\hline Rarely & $41(4)$ \\
Never & $21(2)$
\end{tabular}

Intent to continue engaging in virus-protecting behaviours (mask wearing, social distancing, etc) postvaccine

\begin{tabular}{lc} 
Most of the time & $526(47)$ \\
\hline Some of the time & $343(31)$ \\
\hline Seldom & $94(8)$ \\
Never & $54(5)$ \\
\hline I don't know/prefer not to answer & $95(9)$ \\
\hline Seasonal influenza vaccine over the last 5 years & \\
\hline Every year & $511(46)$ \\
\hline 3-4 years & $163(15)$ \\
1-2 years & $202(18)$ \\
\hline Never & $218(19)$ \\
I don't know/prefer not to answer & $27(2)$ \\
\hline
\end{tabular}

there was much missing data for the ethnicity variable; therefore, this result is considered exploratory only.

- Strong agreement with the VCI questions. For example, strong agreement with the statement 'Vaccines are effective' had an OR=14.6 (95\% CI 10.9 to 19.5 ) for general vaccine and 14.0 (95\% CI 10.4 to 18.9) for SARS-CoV-2 vaccine.

Lower likelihood of vaccine uptake was significantly associated with:

- Being a healthcare worker: with an OR of $0.5(95 \%$ CI 0.3 to 0.8 ) and 0.5 (95\% CI 0.3 to 0.8 ), for general and SARS-CoV-2 vaccines, respectively. However, this is exploratory only due to the small sample of healthcare workers and inability to delineate what worker type (eg, allied health, medical, social worker, etc).

There were no significant findings for educational level, perceived income or residential rurality. 


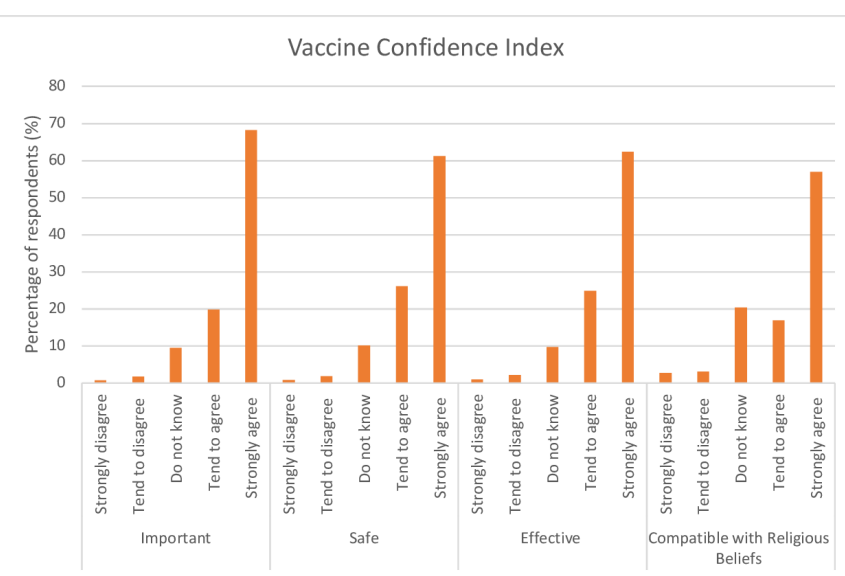

Figure 1 Vaccine confidence index: responses to the questions about if general vaccines are safe, important, effective, and compatible with your religious beliefs.

Differences between the general vaccines and the new COVID-19 vaccines:

- There were no differences between the sexes for the likelihood of general vaccine uptake, while SARSCoV-2 vaccine intention to uptake was significantly higher for men compared with women with OR of 1.37 (95\% CI1.08 to 1.72$)$.

\section{Factors that might influence decisions to get the SARS-CoV-2 vaccine}

Having information that the SARS-CoV-2 vaccine is safe $(85 \%)$, effective $(85 \%)$, will help protect people around the participant $(80 \%)$ and trusting the company who developed the vaccine $(78 \%)$ were reported to influence the participants somewhat or to a great extent to get vaccinated (table 5). A doctor's recommendation $(72 \%)$ and convenience factors $(72 \%)$ were also positive predictor variables for vaccine uptake. Other positive predictors include believing that the participant was at high risk of getting COVID-19 or suffering from severe complications $(69 \%)$, increasing civil liberties $(68 \%)$ and seeing others get vaccinated $(66 \%)$.

\section{Sensitivity analyses}

Bayesian regression analyses produced very similar results to initial logistic regression analyses. The regressions repeated with redichotomising outcomes to include the two most extreme responses instead of one showed similar findings (online supplemental table).

\section{DISCUSSION}

We examined the beliefs, intentions and hesitancy of 1166 Australians towards vaccines in general and to the SARS-CoV-2 vaccine in a large, nationally representative cross-sectional analysis of a surveys in early 2021. Seventyeight per cent of all participants reported being likely to get the SARS-CoV-2 vaccine when it became available to them. Rates of both general vaccine uptake and SARSCoV-2 vaccine uptake increased with age, believing that vaccines are safe and effective, and residing in the least disadvantaged socioeconomic region. Being male was associated with higher intentions to get the SARS-CoV-2 vaccine but had no statistically significant difference to general vaccine intention compared with females. There were no statistically significant differences in education level, perceived income level or rurality and rates of either general or SARS-CoV-2 vaccine acceptance. Strong influencing factors reported to convince people to uptake the SARS-CoV-2 vaccine were: knowing that the SARS$\mathrm{CoV}-2$ vaccine is safe and effective; trusting the vaccine producers; knowing it will help protect people close to them; recommendations from doctors to get vaccinated; and convenience getting the vaccine.

A 2021 study exploring global trends in SARS-CoV-2 vaccine hesitancy found that males, older adults, those with a history of influenza vaccination were less likely to report hesitancy, echoing the findings in our study. ${ }^{29}$ They also found that those living in urban regions and that those who were in the middle or top tiered of perceived income were less likely to be vaccine hesitant, with our study finding no significant relationship between these variables. ${ }^{29}$ Fifty-three per cent of participants in our study indicated that they were extremely likely to get a SARS-CoV-2 vaccine, which was lower than those reported in Brazil $(89 \%)$, Italy $(81 \%)$ (Canada $(71 \%)$ and the UK (80\%), but similar to the USA (57\%) and higher than Turkey and France ( $49 \%$ for both) ${ }^{29}$

The following factors were identified as having more of an influence on vaccination rates and hence could be used to inform public health policies and messaging to enhance vaccination rates. Having knowledge that the SARS-CoV-2 vaccine is safe and effective will encourage a large proportion of the study cohort to get vaccinated. These two factors are encompassed in the VCI and were recently examined in a large international study. ${ }^{21}$ Together, they are likely to play the largest role in the uptake of the SARS-CoV-2 vaccine. Responsible, accurate reporting of the balance of risks and benefits in the media and social media is likely important to build trust in the vaccines and the companies that manufacture them. ${ }^{30}$ Since trust in the vaccine companies is identified as a strong influencing factor in encouraging vaccination, this needs to be reaffirmed by focusing on the stringent regulatory processes the companies must adhere to, which can be conveyed in consistent and transparent public health messaging. Participants also indicated that knowing that the SARS-CoV-2 vaccine would protect those around them was a significant factor influencing intention to vaccinate. While those who are vaccinated can still transmit SARS-CoV2, transmission is decreased meaning family and friends are more protected, ${ }^{31}$ which appeals to prosocial or altruistic attitudes, known to effectively increase vaccination rates. ${ }^{32}$ Another key driver of vaccine uptake likelihood in our study was getting a recommendation from a doctor, aligned with previous immunisation programmes, including in the H1N1 pandemic, and should be encouraged with the 
Table 4 Vaccine uptake determinants: univariate regression analyses with possible predictors that influence general vaccine uptake (left columns) and SARS-CoV-2 vaccine uptake (right columns)

\begin{tabular}{|c|c|c|c|c|c|c|}
\hline & \multirow{2}{*}{\multicolumn{3}{|c|}{$\begin{array}{l}\text { Do you generally accept vaccines for } \\
\text { yourself or for your children? } \\
\text { Outcome: 'Always' versus not }\end{array}$}} & \multirow{2}{*}{\multicolumn{3}{|c|}{$\begin{array}{l}\text { If a vaccine for COVID-19 were available today } \\
\text { what is the likelihood that you would get } \\
\text { vaccinated? } \\
\text { Outcome: 'Extremely likely' versus not }\end{array}$}} \\
\hline & & & & & & \\
\hline & OR & $95 \% \mathrm{Cl}$ & $P$ value & OR & $95 \% \mathrm{Cl}$ & $P$ value \\
\hline \multicolumn{7}{|c|}{ Vaccines confidence (strongly agree vs not strongly agree) } \\
\hline Vaccines are important & 10.6 & 8 to 14.09 & $<0.001$ & 6.73 & 5.09 to 8.9 & $<0.001$ \\
\hline Vaccines are safe & 13.45 & 10.08 to 17.94 & $<0.001$ & 14.67 & 10.92 to 19.71 & $<0.001$ \\
\hline Vaccines are effective & 14.58 & 10.9 to 19.5 & $<0.001$ & 14.02 & 10.42 to 18.86 & $<0.001$ \\
\hline Age (continuous)* & 1.59 & 1.4 to 1.8 & $<0.001$ & 2.01 & 1.77 to 2.27 & $<0.001$ \\
\hline \multicolumn{7}{|l|}{ Sex } \\
\hline Females & (Ref) & - & - & - & - & - \\
\hline Males & 0.93 & 0.73 to 1.18 & 0.543 & 1.37 & 1.08 to 1.72 & 0.008 \\
\hline \multicolumn{7}{|l|}{ Essential worker } \\
\hline No & (Ref) & - & - & - & - & - \\
\hline Yes & 0.72 & 0.52 to 0.995 & 0.047 & 0.65 & 0.47 to 0.9 & 0.009 \\
\hline \multicolumn{7}{|l|}{ Healthcare worker } \\
\hline No & (Ref) & - & - & - & - to - & - \\
\hline Yes & 0.51 & 0.32 to 0.8 & 0.004 & 0.53 & 0.33 to 0.84 & 0.007 \\
\hline \multicolumn{7}{|l|}{ Residential area } \\
\hline Rural/country area & (Ref) & - & - & - & - & - \\
\hline Suburban/regional & 0.89 & 0.6 to 1.31 & 0.551 & 1.12 & 0.78 to 1.62 & 0.528 \\
\hline Urban/city & 0.85 & 0.56 to 1.28 & 0.425 & 1.3 & 0.88 to 1.92 & 0.187 \\
\hline \multicolumn{7}{|l|}{ Major states } \\
\hline Others & (Ref) & - & - & - & - & - \\
\hline $\operatorname{VIC}(1)$ & 1.54 & 1.09 to 2.17 & 0.015 & 2.14 & 1.53 to 2.99 & $<0.001$ \\
\hline QLD (2) & 0.58 & 0.38 to 0.89 & 0.013 & 1.01 & 0.66 to 1.54 & 0.965 \\
\hline NSW (3) & 0.85 & 0.58 to 1.26 & 0.436 & 1.13 & 0.77 to 1.65 & 0.529 \\
\hline \multicolumn{7}{|c|}{ Influenza vaccination (over past 5 years) } \\
\hline Never & (Ref) & - & - & - & - & - \\
\hline Once or twice & 1.28 & 0.87 to 1.89 & 0.209 & 1.46 & 0.96 to 2.22 & 0.074 \\
\hline Three or four & 2.76 & 1.81 to 4.2 & $<0.001$ & 2.53 & 1.64 to 3.89 & $<0.001$ \\
\hline Every year (five times) & 10.55 & 7.25 to 15.36 & $<0.001$ & 8.52 & 5.93 to 12.23 & $<0.001$ \\
\hline \multicolumn{7}{|l|}{ Education level } \\
\hline Primary school or less & (Ref) & - & - & - & - & - \\
\hline Secondary/high school & 1.35 & 0.4 to 4.62 & 0.629 & 1.46 & 0.46 to 4.64 & 0.521 \\
\hline TAFE & 0.83 & 0.24 to 2.82 & 0.766 & 0.96 & 0.3 to 3.04 & 0.942 \\
\hline University degree & 0.82 & 0.24 to 2.79 & 0.753 & 1.06 & 0.33 to 3.35 & 0.927 \\
\hline $\begin{array}{l}\text { Graduate/postgraduate } \\
\text { degree }\end{array}$ & 0.84 & 0.25 to 2.87 & 0.782 & 1.13 & 0.35 to 3.59 & 0.841 \\
\hline \multicolumn{7}{|c|}{ Perceived income level $(231,20.55 \%$ of participants did not want to answer/did not know) } \\
\hline Bottom third & (Ref) & - & - & - & - & - \\
\hline Middle third & 0.86 & 0.63 to 1.17 & 0.324 & 0.81 & 0.61 to 1.09 & 0.168 \\
\hline Top third & 1.24 & 0.8 to 1.93 & 0.329 & 0.97 & 0.65 to 1.46 & 0.9 \\
\hline
\end{tabular}




\begin{tabular}{|c|c|c|c|c|c|c|}
\hline & \multirow{2}{*}{\multicolumn{3}{|c|}{$\begin{array}{l}\text { Do you generally accept vaccines for } \\
\text { yourself or for your children? } \\
\text { Outcome: 'Always' versus not }\end{array}$}} & \multirow{2}{*}{\multicolumn{3}{|c|}{$\begin{array}{l}\text { If a vaccine for COVID-19 were available today, } \\
\text { what is the likelihood that you would get } \\
\text { vaccinated? } \\
\text { Outcome: 'Extremely likely' versus not }\end{array}$}} \\
\hline & & & & & & \\
\hline & OR & $95 \% \mathrm{Cl}$ & $P$ value & OR & $95 \% \mathrm{Cl}$ & P value \\
\hline $\begin{array}{l}\text { Quintile } 1 \text { - most } \\
\text { disadvantaged }\end{array}$ & (Ref) & - & - & - & - & - \\
\hline Quintile 3 & 1.36 & 0.89 to 2.07 & 0.155 & 1.22 & 0.8 to 1.85 & 0.352 \\
\hline Quintile 4 & 1.2 & 0.79 to 1.82 & 0.388 & 1.21 & 0.8 to 1.83 & 0.369 \\
\hline $\begin{array}{l}\text { Quintile } 5 \text { - least } \\
\text { disadvantaged }\end{array}$ & 2.11 & 1.41 to 3.15 & $<0.001$ & 2.27 & 1.53 to 3.37 & $<0.001$ \\
\hline \multicolumn{7}{|l|}{ Ethnicity } \\
\hline
\end{tabular}

Believing that participant is at high risk of COVID-19

\begin{tabular}{llr}
$\begin{array}{l}\text { No/don't know/prefer not } \\
\text { to answer }\end{array}$ & (Ref) & - \\
Yes & 1.52 & 1.08 to 2.14 \\
\hline
\end{tabular}

${ }^{*}$ Age variable is scaled to have a mean of 0 and unit SD.

†Ethnicity data were missing for $n=431$; therefore, results for this variable are exploratory only.

IRSD, index of relative socioeconomic disadvantage.

SARS-CoV-2 vaccine. ${ }^{24}$ Medical professionals will benefit from consistent updated access to accurate information on the SARS-CoV-2 vaccine, countering non-evidence based antivaccination messages, outlining benefits and risks, interpreting evidence as it emerges and personalising it to the individuals who seek care. ${ }^{243}$

Convenience factors such as time needed or travel requirements to get vaccinated have also been identified as a strong influencing factor. This could be why increased local vaccination sites in Australia, including popup clinics at areas such as schools and mosques and shopping centres, alongside the roll-out of mass vaccination hubs, and of vaccinations in General Practice clinics, pharmacies and workplaces, already shown to increase the rate of other vaccinations including the annual influenza vaccine have also assisted in boosting Australia's vaccination rates for COVID- $19 .{ }^{34}$ Here $68 \%$ of participants noted intention to get vaccinated if it offered them increased civil liberties, such as going to concerts or sporting events.

When choosing to get vaccinated, the perceived likelihood of infection, the prevalence and severity of the relevant disease are key in the decision-making process. ${ }^{35} \mathrm{In}$ early 2021 in our study, $72 \%$ of all participants did not believe that they were at a high risk of getting COVID-19, likely reflecting the low numbers of infections, hospitalisations and deaths in Australia at that time. ${ }^{36}$ Misinformation in the media also equated COVID-19 severity to that of the seasonal influenza. ${ }^{37}$ These factors are likely to have presented obstacles to initial vaccination uptake in Australia, with participants who perceived a higher risk of getting COVID-19 reported a 50\% higher likelihood of getting vaccinated. Previous research on the SARS-CoV-2 vaccine, as well as vaccination research during the 2009 H1N1 pandemic echo our results. ${ }^{33} 38$ Leveraging anticipated regret, shown to be one of the strongest predictors for vaccine intention, could also be further explored to enhance SARS-CoV-2 vaccination rates. ${ }^{33} 39$ Consistent with other early surveys, ${ }^{40}$ we noted that men report the most willingness to receive a SARS-CoV-2 vaccine; however, this intention may not translate to gender differences in vaccination uptake. ${ }^{41}$

Exploratory findings based on a small sample suggested that healthcare workers and those not identifying themselves being from Australia/NZ/UK were less likely to accept both general and the SARS-CoV-2 vaccines. Considering the influence that healthcare workers have on the general population, plus their high exposure rates to the virus, this presents a barrier to both effective vaccine uptake and to infection rates control. A 2021 review found an average of $23 \%$ (range: $4 \%-72 \%$ ) of healthcare workers reported vaccine hesitancy. The review also found that being male, older and a doctor were associated with higher rates of SARS-CoV-2 vaccine acceptance in healthcare workers. ${ }^{42}$ The current study did not delineate between types of healthcare workers (eg, doctors, nurses and allied health). Our findings also identified a higher rate of vaccine hesitancy in people who did not 
Table 5 Factors reported by $\mathrm{n}=1081$ Australians that may influence intent to get the SARS-CoV-2 vaccine

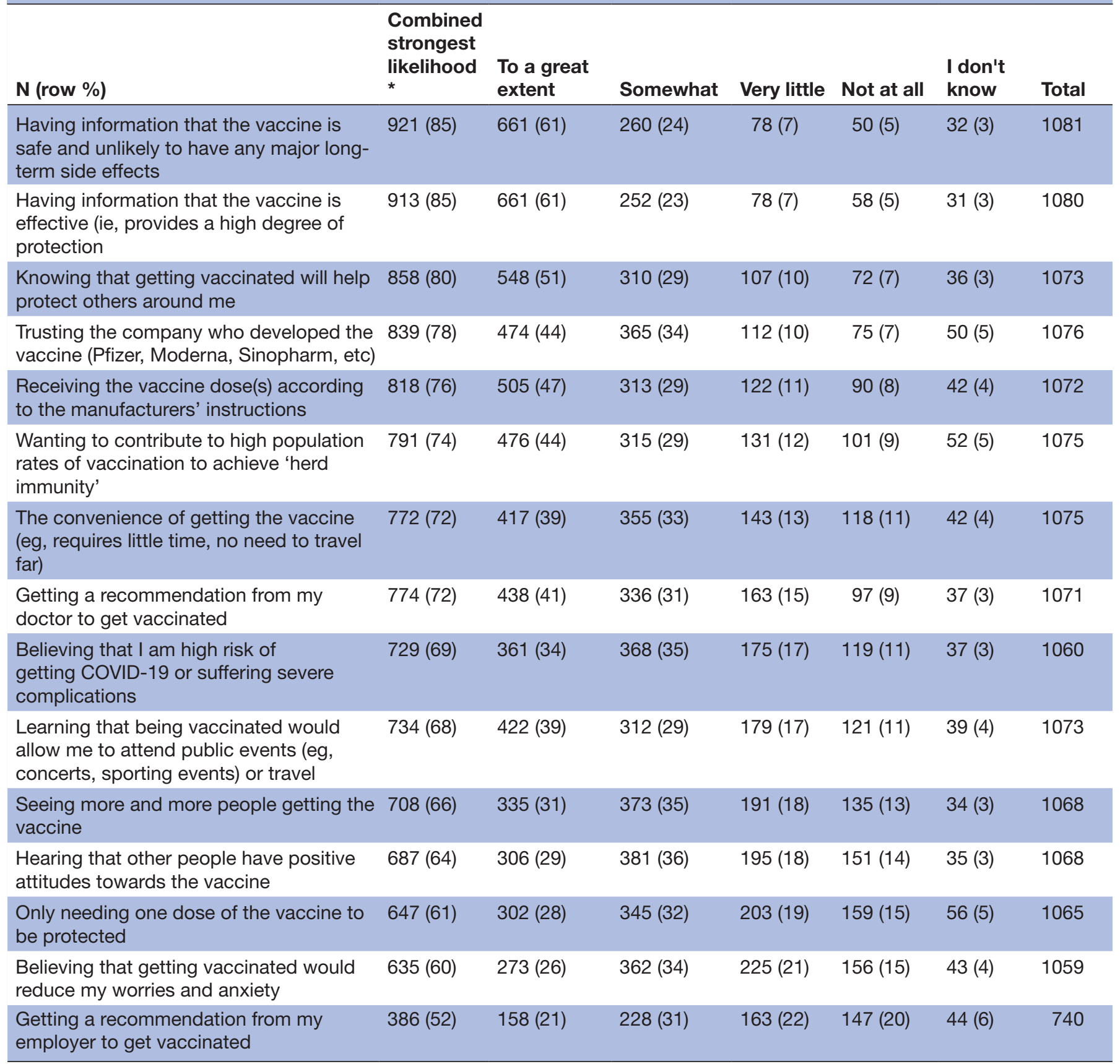

*Combined 'somewhat' and 'to a great extent' responses. Influencing factors are ranked in descending order, from most likely to influence SARS-CoV-2 vaccine uptake to least likely.

identify their ethnicity as Australian/New Zealanders or UK groups, consistent with past research in this and other vaccines. ${ }^{33}$ However, the findings for both these high-risk groups need to be interpreted with caution due to the small sample size. More data here could aid in further targeting policy-based communications and interventions.

Public health authorities need to provide transparent, easy to interpret information on the SARSCoV-2 vaccines to the general population, as highlighted by Eastwood $e t a t^{33}$ during the H1N1 pandemic. This will aid in alleviating the confusion which may stem from misinformation present in the media and online networks. Furthermore, we echo the suggestions made in Seale et $a l,{ }^{44}$ which includes tailoring messages and engaging community leaders in disseminating information about vaccines in culturally and linguistically diverse groups, with the known influence of social groups and community leaders of similar backgrounds. For healthcare workers, engagement and education is important, given the important role they play in modelling healthpromoting behaviour for the general public. ${ }^{37}$ Mandatory 
influenza vaccination is already in place for many healthcare workers in Australia, and mandatory SARS-CoV2 vaccination has been introduced for aged care workers and for healthcare workers in all states and territories. ${ }^{42}$ This may have contributed to increased vaccine uptake with recent government figures indicating that in the majority of regions $>90 \%$ of aged care workers are fully vaccinated.$^{45}$ Furthermore, anecdotally, it appears that the majority of those working in other health facilities have been vaccinated with minimal numbers standing down for refusing the SARS-CoV2 vaccine since the mandatory policy was introduced. Healthcare workers beliefs and attitudes to the SARS-CoV2 vaccine may reflect similar concerns to their broader community as seen in the UK with hesitancy being more frequent in non-white British healthcare workers, female sex and younger age ${ }^{46}$ Understanding the impact of mandates, knowledge, attitudes and beliefs driving this behaviour remains important given the risks to staff and patients and the need for booster (or third dose) vaccines in the ongoing pandemic.

The strengths of our study include a large, generally representative sample across Australia and evidence based approaches including the vaccine confidence index. Limitations to our study include that this the survey was only available in English, which is likely to have reduced representation of ethnic groups. Internet access was required, which may account for the increased representation of those in the least disadvantaged quintile. Future studies should address these issues in order to characterise vaccine intentions and attitudes in more remote and higher risk groups. Furthermore, since we rely on self-reported behaviour, there is the risk of a social desirability bias, with participants potentially overreporting socially desirable traits in their responses and the voluntary nature of the survey makes it prone to a selection bias. ${ }^{97}$ Also the response rate of $10 \%$ for new participants is a limitation that possibly introduced nonresponder bias, and further studies with greater resources to limit this bias by employing additional strategies such as telephone recruitment and hard copy surveys could be conducted. $^{48}$

There is a paucity of studies on what influences people to consider taking the vaccine in Australia in 2021, where access to the SARS-CoV-2 vaccines is increasing but still limited by age and occupation at the time of the survey. Since this study, the rapid emergence of the highly transmissibile Delta and Omicron variants combined with the major challenges of large-scale extended lockdowns, are escalating the imperative for rapid vaccination and highlighting the importance of work in this field. Behavioural research such as the iCARE study can inform policymakers in understanding the public's knowledge, attitudes, perceptions and beliefs towards the SARS-CoV-2 vaccine, which in turn drive their behaviours including vaccination and can aid with targeting public health messages. $^{24}$

\section{CONCLUSION}

Given the worldwide morbidity, hospitalisation and death from COVID-19, the established safety and effectiveness of widely tested vaccines to prevent these complications and the imperative to accelerate vaccination globally including in Australia, the results of this study on vaccine hesitancy are important. Here we show that vaccine safety, effectiveness, trust in the companies and recommendations from doctors are important determinants of vaccine intentions. Further work to understand vaccine hesitancy in identified target groups including culturally and linguistically diverse groups and healthcare workers are important moving forward to support equity in vaccine uptake. This work can directly inform strategies to optimise communication and SARS-CoV-2 vaccine uptake, especially in Australia, now vital as the Delta variant takes a grip on the country.

\section{Author affiliations}

${ }^{1}$ Monash Centre for Health Research and Implementation, School of Public Health and Preventive Medicine, Monash University, Clayton, Victoria, Australia

${ }^{2}$ Monash Partners Academic Health Science Centre, Melbourne, Victoria, Australia ${ }^{3}$ Montreal Behavioural Medicine Centre, CIUSSS du Nord-de-l'Ile-de-Montreal,

Montreal, Québec, Canada

${ }^{4}$ Department of Health, Kinesiology and Applied Physiology, Concordia University, Montreal, Québec, Canada

${ }^{5}$ Department of Psychology, University of Quebec in Montreal, Montreal, Québec, Canada

${ }^{6}$ Department of General Practice, Monash University, Clayton, Victoria, Australia ${ }^{7}$ School of Public Health and Preventive Medicine, Monash University, Melbourne, Victoria, Australia

\section{Twitter Joanne Enticott @EnticottJo}

Acknowledgements KLL is a member of the Canadian COVID-19 Expert Advisory Panel (Health Canada).

Collaborators iCARE Study Team iCARE Study Collaborators: lead investigators: Kim L Lavoie, PhD, University of Quebec at Montreal (UQAM) and CIUSSS-NIM, Canada; Simon L Bacon, PhD, Concordia University and CIUSSS-NIM, Canada. Collaborators (in alphabetical order by country): Abu Dhabi: Zahir Vally, PhD, United Arab Emirates University; Argentina: Analía Verónica Losada, PhD, University of Flores; Australia: Jacqueline Boyle, PhD, Monash University; Joanne Enticott, PhD, Monash University; Shajedur Rahman Shawon, PhD, Centre for Big Data Research in Health, UNSW Medicine; Helena Teede, MD, Monash University; Austria: Alexandra Kautzky-Willer, MD, Medizinische Universität Wien; Bangladesh: Arobindu Dash, MS, International University of Business, Agriculture; Brazil: Marilia Estevam Cornelio, PhD, University of Campinas; Marlus Karsten, Universidade do Estado de Santa Catarina - UDESC; Darlan Lauricio Matte, PhD, Universidade do Estado de Santa Catarina - UDESC; Canada: Ahmed Abou-Setta, PhD, University of Manitoba; Shawn Aaron, PhD, Ottawa Hospital Research Institute; Angela Alberga, PhD, Concordia University; Tracie Barnett, PhD, McGill University; Silvana Barone, MD, Université de Montréal; Ariane Bélanger-Gravel, PhD, Université Laval; Sarah Bernard, PhD, Université Laval; Lisa Maureen Birch, PhD, Université Laval; Susan Bondy, PhD, University of Toronto - Dalla Lana School of Public Health; Linda Booij, PhD, Concordia University; Roxane Borgès Da Silva, PhD, Université de Montréal; Jean Bourbeau, MD, McGill University; Rachel Burns, PhD, Carleton University; Tavis Campbell, PhD, University of Calgary; Linda Carlson, PhD, University of Calgary; Kim Corace, PhD, University of Ottawa; Olivier Drouin, MD, CHU Sainte-Justine/ Université de Montréal; Francine Ducharme, MD, Université de Montréal; Mohsen Farhadloo, Concordia University; Carl Falk, PhD, McGill University; Richard Fleet MD, PhD, Université Laval; Michel Fournier, MSc, Direction de la Santé Publique de Montréal; Gary Garber, MD, University of Ottawa/Public Health Ontario; Lise Gauvin, $\mathrm{PhD}$, Université de Montréal; Jennifer Gordon, PhD, University of Regina; Roland Grad, MD, McGill University; Samir Gupta, MD, University of Toronto; Kim Hellemans, PhD, Carleton University; Catherine Herba PhD, UQAM; Heungsun Hwang, PhD, McGill University; Jack Jedwab, PhD, Canadian Institute for Identities and Migration and the Association for Canadian Studies; Keven Joyal-Desmarais, PhD, Concordia 
University; Lisa Kakinami, PhD, Concordia University; Eric Kennedy, PhD, York University; Sunmee Kim, PhD, University of Manitoba; Joanne Liu, PhD, McGill University; Colleen Norris, PhD, University of Alberta; Sandra Pelaez, PhD, Université de Montréal; Louise Pilote, MD, McGill University; Paul Poirier, MD, Université Laval; Justin Presseau, PhD, University of Ottawa; Eli Puterman, PhD, University of British Columbia; Joshua Rash, PhD, Memorial University; Paula AB Ribeiro, PhD, MBMC; Mohsen Sadatsafavi, PhD, University of British Columbia; Paramita Saha Chaudhuri, PhD, McGill University; Jovana Stojanovic, PhD, Concordia University; Eva Suarthana, MD, PhD, Université de Montréal/McGill University; Sze Man Tse, MD, CHU Sainte-Justine; Michael Vallis, PhD, Dalhousie University; Chile: Nicolás Bronfman Caceres, PhD, Universidad Andrés Bello; Manuel Ortiz, PhD, Universidad de La Frontera; Paula Beatriz Repetto, PhD, Universidad Católica de Chile; Colombia: Mariantonia Lemos-Hoyos, PhD, Universidad EAFIT; Cyprus: Angelos Kassianos, PhD, University of Cyprus; Denmark: Naja Hulvej Rod, PhD, University of Copenhagen; France: Mathieu Beraneck, PhD, Université de Paris; CNRS; Gregory Ninot, PhD, Université de Montpellier; Germany: Beate Ditzen, PhD, Heidelberg University; Thomas Kubiak, PhD, Mainz University; Ghana: Sam Codjoe, MPhil,MSc, University of Ghana; Lily Kpobi, PhD, University of Ghana; Amos Laar, PhD, University of Ghana; India: Naorem Kiranmala Devi, PhD, University of Delhi; Sanjenbam Meitei, PhD, Manipur University; Suzanne Tanya Nethan, MDS, ICMR-National Institute of Cancer Prevention; Lancelot Pinto, MD, PhD, Hinduja Hospital and Medical Research Centre; Kallur Nava Saraswathy, PhD, University of Delhi; Dheeraj Tumu, MD, World Health Organization (WHO); Indonesia: Silviana Lestari, MD, PhD, Universitas Indonesia; Grace Wangge, MD, PhD, SEAMEO Regional Center for Food and Nutrition; Ireland: Molly Byrne, PhD, National University of Ireland, Galway; Hannah Durand, PhD, National University of Ireland, Galway; Jennifer McSharry, PhD, National University of Ireland, Galway; Oonagh Meade, $\mathrm{PhD}$, National University of Ireland, Galway; Gerry Molloy, PhD, National University of Ireland, Galway; Chris Noone, PhD, National University of Ireland, Galway; Israel: Hagai Levine, MD, Hebrew University; Anat Zaidman-Zait, PhD, Tel-Aviv University; Italy: Stefania Boccia, PhD, Università Cattolica del Sacro Cuore; Ilda Hoxhaj, MD, Università Cattolica del Sacro Cuore; Stefania Paduano, MSc, PhD, University of Modena and Reggio Emilia; Valeria Raparelli, PhD, Sapienza - University of Rome; Drieda Zaçe, MD, MSc, PhDc, Università Cattolica del Sacro Cuore; Jordan: Ala'S Aburub, PhD, Isra University; Kenya: Daniel Akunga, PhD, Kenyatta University; Richard Ayah, PhD, University of Nairobi, School Public Health; Chris Barasa, MPH, University of Nairobi, School Public Health; Pamela Miloya Godia, PhD, University of Nairobi; Elizabeth W Kimani-Murage, PhD, African Population and Health Research Center; Nicholas Mutuku, PhD, University of Kenya; Teresa Mwoma, PhD, Kenyatta University; Violet Naanyu, PhD, Moi University; Jackim Nyamari, PhD, Kenyatta University; Hildah Oburu, PhD, Kenyatta University; Joyce Olenja, PhD, University of Nairobi; Dismas Ongore, PhD, University of Nairobi; Abdhalah Ziraba, PhD, African Population and Health Research Center; Malawi: Chiwoza Bandawe, PhD, University of Malawi; Malaysia: Loh Siew Yim, PhD, Faculty of medicine, University of Malaya; New Zealand: Andrea Herbert, PhD, University of Canterbury; Daniela Liggett, PhD, University of Canterbury; Nigeria: Ademola Ajuwon, PhD, University of Ibadan; Pakistan: Nisar Ahmed Shar, PhD, CoPI-National Center in Big Data; Bilal Ahmed Usmani, PhD, NED University of Engineering and Technology; Peru: Rosario Mercedes Bartolini Martínez, PhD, Instituto de Investigacion Nutricional; Hilary Creed-Kanashiro, M.Phil., Instituto de Investigacion Nutricional; Portugal: Paula Simão, MD, S. Pneumologia de Matosinhos; Rwanda: Pierre Claver Rutayisire, PhD, University Rwanda; Saudi Arabia: Abu Zeeshan Bari, PhD, Taibah University; Slovakia: Iveta Nagyova, PhD, PJ Safarik University - UPJS; South Africa: Jason Bantjes, PhD, University of Stellenbosch; Brendon Barnes, PhD, University of Johannesburg; Bronwyne Coetzee, PhD, University of Stellenbosch; Ashraf Khagee, $\mathrm{PhD}$, University of Stellenbosch; Tebogo Mothiba, PhD, University of Limpopo; Rizwana Roomaney, PhD, University of Stellenbosch; Leslie Swartz, PhD University of Stellenbosch; South Korea: Juhee Cho, PhD, Sungkyunkwan University; Man-gyeong Lee, PhDc, Sungkyunkwan University; Sweden: Anne Berman, PhD, Karolinska Institutet; Nouha Saleh Stattin, MD, Karolinska Institutet; Switzerland: Susanne Fischer, PhD, University of Zurich; Taiwan: Debbie Hu, MD, MSc, Tainan Municipal Hospital; Turkey: Yasin Kara, MD, Kanuni Sultan Süleyman Training and Research Hospital, Istanbul; Ceprail Şimşek, MD Health Science University; Bilge Üzmezoğlu, MD, University of Health Science; Uganda: John Bosco Isunju, PhD, Makerere University School of Public Health; James Mugisha, PhD, University of Uganda; UK: Lucie Byrne-Davis, PhD, University of Manchester; Paula Griffiths, PhD, Loughborough University; Joanne Hart, PhD, University of Manchester; Will Johnson, $\mathrm{PhD}$, Loughborough University; Susan Michie, PhD, University College London; Nicola Paine, PhD, Loughborough University; Emily Petherick, PhD, Loughborough University; Lauren Sherar, PhD, Loughborough University; USA: Robert M Bilder, PhD, ABPP-CN, University of California, Los Angeles; Matthew Burg, PhD, Yale; Susan Czajkowski, PhD, NIH - National Cancer Institute; Ken Freedland, PhD,
Washington University; Sherri Sheinfeld Gorin, PhD, University of Michigan; Alison Holman, PhD, University of California, Irvine; Jiyoung Lee, PhD, University of Alabama; Gilberto Lopez, ScD, MA, MPH, Arizona State University and University of Rochester Medical Center; Sylvie Naar, PhD, Florida State University; Michele Okun, $\mathrm{PhD}$, University of Colorado, Colorado Springs; Lynda Powell, PhD, Rush University; Sarah Pressman, PhD, University of California, Irvine; Tracey Revenson, PhD, University of New York City; John Ruiz, PhD, University ofArizona; Sudha Sivaram, $\mathrm{PhD}$, NIH, Center for Global Health; Johannes Thrul, PhD, Johns Hopkins; Claudia Trudel-Fitzgerald, PhD, Harvard T.H. Chan School of Public Health; Abehaw Yohannes, PhD, Azusa Pacific University. Students: Australia: Rhea Navani, BSc, Monash University; Kushnan Ranakombu, PhD, Monash University; Brazil: Daisuke Hayashi Neto, Unicamp; Canada: Tair Ben-Porat, PhD, Tel Aviv University; Anda Dragomir, University of Quebec at Montreal (UQAM) and CIUSSS-NIM; Amandine Gagnon-Hébert, BA, UQAM; Claudia Gemme, MSc, UQAM; Vincent Gosselin Boucher, University of Quebec at Montreal (UQAM) and CIUSSS-NIM; Mahrukh Jamil, Concordia University and CIUSSS-NIM; Lisa Maria Käfer, McGill University; Ariany Marques Vieira, MSc, Concordia University; Tasfia Tasbih, Concordia University and CIUSSS-NIM; Maegan Trottier, University of Lethbridge; Robbie Woods, MSc, Concordia University; Reyhaneh Yousefi, Concordia University and CIUSSS-NIM; France: Tamila Roslyakova, Université de Montpellier; Germany: Lilli Priesterroth, Mainz University; Israel: Shirly Edelstein, Hebrew University-Hadassah School of Public Health; Tanya Goldfrad, Hebrew University-Hadassah School of Public Health; Ruth Snir, Hebrew University-Hadassah School of Public Health; Yifat Uri, Hebrew University-Hadassah School of Public Health; New Zealand: Mohsen Alyami, University of Auckland; Nigeria: Comfort Sanuade; Serbia: Katarina Vojvodic, University of Belgrade. Community Participants: Canada: Olivia Crescenzi; Kyle Warkentin; Denmark: Katya Grinko; India: Lalita Angne; Jigisha Jain; Nikita Mathur, Syncorp Clinical Research; Anagha Mithe; Sarah Nethan, Community Empowerment Lab.

Contributors SLB and KLL led study conceptualisation. JE, SD and JSG were responsible for the statistical analyses. JSG and JE wrote the first draft of the paper, with early input from DE. JB and HJT are the senior authors and guarantors. All authors contributed to the development of the research question, study design in relation to the Australian data analysis, interpretation of the results, critical revision of the manuscript for important intellectual content and approved the final version of the manuscript. JB attests that all listed authors meet authorship criteria and that no others meeting the criteria have been omitted.

Funding The primary source of funding for the iCARE study has been provided by the Canadian Institutes of Health Research (MS3-173099, co-PI's: SLB and KLL) and the Fonds de Recherche du Québec: Société et Culture (2019-SE1-252541, PI: $\mathrm{SLB})$. Additional support has been provided through redirected funding associated with Montreal Behavioural Medicine Centre, including funds from the Canada Research Chairs Program (950-232522, chair holder: KLL), a Canadian Institutes of Health Research-Strategy for Patient Oriented Research Mentoring Chair (SMC151518, PI: SLB), a Fonds de Recherche du Québec: Santé Chair (251618, PI: SLB) and a Fonds de Recherche du Québec: Santé Senior Research Award (34757, PI: $\mathrm{KLL})$.

Competing interests SLB has received consultancy fees from Merck for the development of behavior change continuing education modules, speaker fees from Novartis and Janssen and has served on advisory boards for Bayer, Sanofi and Sojecci Inc, none of which are related to the current article. KLL has served on the advisory board for Schering-Plough, Takeda, AbbVie, Almirall, Janssen, GSK, Novartis, Boehringer Ingelheim (BI) and Sojecci Inc, and has received sponsorship for investigator-generated research grants from GlaxoSmithKline (GSK) and AbbVie, speaker fees from GSK, AstraZeneca, Astellas, Novartis, Takeda, AbbVie, Merck, Boehringer Ingelheim, Bayer, Pfizer, Xfacto and Air Liquide, and support for educational materials from Merck, none of which are related to the current article. The authors declare that the research was conducted in the absence of any commercial or financial relationships that could be construed as a potential conflict of interest.

\section{Patient consent for publication Not applicable.}

Ethics approval The studies involving human participants were reviewed and approved by Monash University Human Research Ethics Committee (MUHREC Project ID: 24449). The patients/participants provided their written informed consent to participate in this study. The Montreal Behavioural Medicine Centre, the lead institution, has research ethics board approval from the Comité d'éthique de la recherche du CIUSSS-NIM (Centre intégré universitaire de santé et de services sociaux du Nord-de-l'île-de-Montréal), approval\#: 2020-2099/25-03-2020.

Provenance and peer review Not commissioned; externally peer reviewed. 
Data availability statement Data are available in a public, open access repository. Data can be made available to approved researchers by contacting the corresponding author. The iCARE study is an open access study. Data access procedures are available at $\mathrm{https}: / / \mathrm{mbmc}-\mathrm{cmcm} . \mathrm{ca} /$ covid19/apl/. Planned analyses are logged at https://mbmc-cmcm.ca/covid19/apl/log/.

Supplemental material This content has been supplied by the author(s). It has not been vetted by BMJ Publishing Group Limited (BMJ) and may not have been peer-reviewed. Any opinions or recommendations discussed are solely those of the author(s) and are not endorsed by BMJ. BMJ disclaims all liability and responsibility arising from any reliance placed on the content. Where the content includes any translated material, BMJ does not warrant the accuracy and reliability of the translations (including but not limited to local regulations, clinical guidelines, terminology, drug names and drug dosages), and is not responsible for any error and/or omissions arising from translation and adaptation or otherwise.

Open access This is an open access article distributed in accordance with the Creative Commons Attribution Non Commercial (CC BY-NC 4.0) license, which permits others to distribute, remix, adapt, build upon this work non-commercially, and license their derivative works on different terms, provided the original work is properly cited, appropriate credit is given, any changes made indicated, and the use is non-commercial. See: http://creativecommons.org/licenses/by-nc/4.0/.

\section{ORCID iDs}

Joanne Enticott http://orcid.org/0000-0002-4480-5690

Jaskirath Singh Gill http://orcid.org/0000-0002-3310-758X

Simon L. Bacon http://orcid.org/0000-0001-7075-0358

Kim L. Lavoie http://orcid.org/0000-0003-2606-1357

Daniel S. Epstein http://orcid.org/0000-0003-2215-7749

\section{REFERENCES}

1 World Health Organisation. Who coronavirus (COVID-19) Dashboard, 2021. Available: https://covid19.who.int/ [Accessed Jun 2021].

2 McCallum H. How will Delta evolve? Here's what the theory tells us. The Conversation, 2021.

3 Henry DA, Jones MA, Stehlik P, et al. Effectiveness of COVID-19 vaccines: findings from real world studies. Med $J$ Aust 2021;215:149-51.

4 Hunter P. The spread of the COVID-19 coronavirus. EMBO reports 2020;21:e50334.

5 Torjesen I. Covid-19 will become endemic but with decreased potency over time, scientists believe. BMJ 2021;372:n494.

6 Paul E, Steptoe A, Fancourt D. Attitudes towards vaccines and intention to vaccinate against COVID-19: implications for public health communications. The Lancet Regional Health - Europe 2021;1:100012.

7 Centers for Disease Control and Prevention. Interim Public Health Recommendations for Fully Vaccinated People: U.S. Department of Health \& Human Services, 2021. Available: https://www.cdc.gov/ coronavirus/2019-ncov/vaccines/fully-vaccinated-guidance.html [Accessed Aug 2021].

8 Borriello A, Master D, Pellegrini A, et al. Preferences for a COVID-19 vaccine in Australia. Vaccine 2021;39:473-9.

9 Enticott J, Slifirski W, Lavoie KL, et al. Knowledge, attitude, and self-reported practice towards measures for prevention of the spread of COVID-19 among Australians: a nationwide online longitudinal representative survey. Front Public Health 2021;9:630189.

10 Sharpe HR, Gilbride C, Allen E, et al. The early landscape of coronavirus disease 2019 vaccine development in the UK and rest of the world. Immunology 2020;160:223-32.

11 Scott N, Saul A, Spelman T, et al. The introduction of a mandatory mask policy was associated with significantly reduced COVID-19 cases in a major metropolitan City. PLoS One 2021;16:e253510.

12 Holley A, Coatsworth N, Lipman J. The Australian response to the COVID-19 pandemic: a co-ordinated and effective strategy. Anaesth Crit Care Pain Med 2021;40:100859.

13 World Health Organization. Hepatitis B (HepB3) immunization coverage among 1-year-olds (\%), 2021. Available: https://www.who. int/data/gho/data/indicators/indicator-details/GHO/hepatitis-b-( hepb3)-immunization-coverage-among-1-year-olds-(-) [Accessed Nov 2021].

14 Kenyon G. Australia's struggle with the delta variant. Lancet Infect Dis 2021;21:1358.

15 Aschwanden C. Five reasons why COVID herd immunity is probably impossible: Springer nature limited, 2021. Available: https://www. nature.com/articles/d41586-021-00728-2 [Accessed Aug 2021].
16 Larson HJ, de Figueiredo A, Xiahong Z, et al. The state of vaccine confidence 2016: global insights through a 67-Country survey. EBioMedicine 2016;12:295-301.

17 Badur S, Ota M, Öztürk S, et al. Vaccine confidence: the keys to restoring trust. Hum Vaccin Immunother 2020;16:1007-17.

18 MacDonald NE, Eskola J, Liang X, SAGE Working Group on Vaccine Hesitancy. Vaccine hesitancy: definition, scope and determinants. Vaccine 2015;33:4161-4.

19 Al-Amer R, Maneze D, Everett B, et al. COVID-19 vaccination intention in the first year of the pandemic: a systematic review. $J$ Clin Nurs 2022;31:62-86.

20 Peretti-Watel P, Seror V, Cortaredona S, et al. A future vaccination campaign against COVID-19 at risk of vaccine hesitancy and politicisation. Lancet Infect Dis 2020;20:769-70.

21 de Figueiredo A, Simas C, Karafillakis E, et al. Mapping global trends in vaccine confidence and investigating barriers to vaccine uptake: a large-scale retrospective temporal modelling study. The Lancet 2020;396:898-908.

22 Dodd $\mathrm{RH}$, Cvejic $\mathrm{E}$, Bonner $\mathrm{C}$, et al. Willingness to vaccinate against COVID-19 in Australia. Lancet Infect Dis 2021;21:318-9.

23 Rhodes A, Hoq M, Measey M-A, et al. Intention to vaccinate against COVID-19 in Australia. Lancet Infect Dis 2021;21:e110.

24 Danchin M, Biezen R, Manski-Nankervis J-A, et al. Preparing the public for COVID-19 vaccines: how can general practitioners build vaccine confidence and optimise uptake for themselves and their patients? Aust J Gen Pract 2020;49:625-9.

25 Bacon SL, Lavoie KL, Boyle J, et al. International assessment of the link between COVID-19 related attitudes, concerns and behaviours in relation to public health policies: optimising policy strategies to improve health, economic and quality of life outcomes (the iCARE study). BMJ Open 2021;11:e046127.

26 Montreal Behavioural Medicine Centre. MBMC, 2020. Available: https://mbmc-cmcm.ca/ [Accessed 01 Jul 2021].

27 Enticott J, Slifirski W, Lavoie KL, et al. Knowledge, attitude, and self-reported practice towards measures for prevention of the spread of COVID-19 among Australians: a nationwide online longitudinal representative survey. Front Public Health 2021;9:630189.

28 Australian Bureau of Statistics. Census of population and housing: socio-economic indexes for areas (SEIFA), 2016. Available: https:// www.abs.gov.au/AUSSTATS/abs@.nsf/DetailsPage/2033.0.55. 0012016?OpenDocument [Accessed 23 Jul 2020]

29 Stojanovic J, Boucher VG, Gagne M, et al. Global trends and correlates of COVID-19 vaccination Hesitancy: findings from the iCARE study. Vaccines 2021;9:661.

30 Nazaroff D. May cause side effects: how social media could be affecting COVID vaccine hesitancy New South Wales. Australia: UNSW, 2021. https://newsroom.unsw.edu.au/news/science-tech/ may-cause-side-effects-how-social-media-could-be-affecting-covidvaccine-hesitancy

31 Lipsitch M, Dean NE. Understanding COVID-19 vaccine efficacy. Science 2020;370:763-5.

32 Chou W-YS, Budenz A. Considering emotion in COVID-19 vaccine communication: addressing vaccine Hesitancy and fostering vaccine confidence. Health Commun 2020;35:1718-22.

33 Seale $\mathrm{H}$, Heywood AE, Leask J, et al. Examining Australian public perceptions and behaviors towards a future COVID-19 vaccine. BMC Infect Dis 2021;21:120.

34 Razai MS, Oakeshott P, Esmail A, et al. COVID-19 vaccine hesitancy: the five Cs to tackle behavioural and sociodemographic factors. $J R$ Soc Med 2021;114:295-8.

35 Sadique MZ, Devlin N, Edmunds WJ, et al. The effect of perceived risks on the demand for vaccination: results from a discrete choice experiment. PLoS One 2013;8:e54149.

36 Park T, Ju I, Ohs JE, et al. Optimistic bias and preventive behavioral engagement in the context of COVID-19. Res Social Adm Pharm 2021;17:1859-66.

37 Stojanovic J, Boucher VG, Boyle J, et al. COVID-19 is not the flu: four graphs from four countries. Front Public Health 2021;9:628479.

38 Karlsson LC, Soveri A, Lewandowsky S, et al. Fearing the disease or the vaccine: the case of COVID-19. Pers Individ Dif 2021;172:110590.

39 Wolff K. COVID-19 vaccination intentions: the theory of planned behavior, optimistic bias, and anticipated regret. Front Psychol 2021:12:648289.

40 Melbourne Institute. Tracking COVID-19 vaccine hesitancy across Australia using taking the pulse of the nation (TTPN) survey data, 2021. Available: https://melbourneinstitute.unimelb.edu.au/ publications/research-insights/ttpn/vaccination-report [Accessed 30 Aug 2021]. 
41 Evagora-Campbell M, Borkotoky K, Sharma S, et al. From routine data collection to policy design: sex and gender both matter in COVID-19. Lancet 2021;397:2447-9.

42 Biswas N, Mustapha T, Khubchandani J, et al. The nature and extent of COVID-19 vaccination Hesitancy in healthcare workers. $J$ Community Health 2021;46:1244-51.

43 Eastwood K, Durrheim DN, Jones A, et al. Acceptance of pandemic (H1N1) 2009 influenza vaccination by the Australian public. Med $J$ Aust 2010;192:33-6.

44 Mileti DS, Darlington JD. The role of searching in shaping reactions to earthquake risk information. Soc Probl 1997;44:89-103.

45 Health' Do. Residential aged care worker COVID-19 vaccination rates map: Australian government. Available: https://www.health.gov. au/resources/apps-and-tools/residential-aged-care-worker-covid19-vaccination-rates-map/residential-aged-care-worker-covid-19vaccination-rates-map

46 Woolf K, McManus IC, Martin CA, et al. Ethnic differences in SARSCoV-2 vaccine hesitancy in United Kingdom healthcare workers: results from the UK-REACH prospective nationwide cohort study. Lancet Reg Health Eur 2021;9:100180.

47 Rosenman R, Tennekoon V, Hill LG. Measuring bias in self-reported data. IJBHR 2011;2:320-32.

48 Galea S, Tracy M. Participation rates in epidemiologic studies. Ann Epidemiol 2007;17:643-53.

49 Australian Bureau of Statistics. Data from: national, state and territory population, 2021. Available: https://wwwabsgovau/statistics/ people/population/national-state-and-territory-population/mar-2021 [Accessed Nov 2021].

50 Australian Bureau of Statistics. Data from: regional population, 2021. Available: https://wwwabsgovau/statistics/people/population/ regional-population/2019-20 [Accessed Nov 2021].

51 Australian Bureau of Statistics. Data from: education and work, Australia, 2021. Available: https://wwwabsgovau/statistics/people/ education/education-and-work-australia/latest-release\#datadownload [Accessed Nov 2021]. 